\title{
Low-Cost Digital Tools for Archaeology
}

\author{
Luca Perfetti, Francesco Fassi and Corinna Rossi
}

\begin{abstract}
Modern technology offers elaborated and efficient instruments capable of performing extremely accurate surveys of architectural and archaeological remains. However, not all of them can be used everywhere: archaeological missions might be constrained by logistics, environmental and, especially, financial restrictions. This issue is especially felt by archaeological missions currently operating in the Middle East and Africa. The research team of the ERC project LIFE (CoGrant 681673) has been successfully experimenting with the use of low-cost instruments to achieve equally accurate results.
\end{abstract}

Keywords Photogrammetry $\cdot$ Low-cost 3D $\cdot$ Fisheye $\cdot$ Action camera

\section{Introduction}

Modern 3D scanner technology is widely used throughout archaeology. Accessing the latest technological tools is often directly related to the availability of substantial funding and to the actual possibility of being able to use them on the field. For these reasons, operators not endowed with sufficient economic resources and/or who are engaged in difficult logistic and environmental situations run the risk of encountering a number of difficulties.

However, nowadays, a new generation of 'image-based survey techniques' can be used to achieve equally satisfactory results in terms of accuracy and completeness of the results: those relying on low-cost instruments and procedures, based on the concepts of flexibility, portability and ease of use. For archaeological projects and for complex conditions of acquisition, as well as, in general, for the vast field of cultural heritage, this type of technique is rapidly becoming the main solution for documenting excavations, findings and archaeological remains.

L. Perfetti $(\varangle) \cdot$ F. Fassi · C. Rossi

Architecture, Built Environment and Construction Engineering-ABC Department, Politecnico di Milano, Milan, Italy

e-mail: luca.perfetti@polimi.it 


\section{Photogrammetry: The Low-Cost Digital Solution}

In the last century, photogrammetry was mainly used to survey the territory and produce cartography. Following the first decades of development of photogrammetry, mainly in the aerial field, close-range photogrammetry for archaeology or architecture could not fully assert itself, since similar technologies and the manual procedures of orientation and stereoplotting were perceived as time-consuming, and consequently very expensive.

Seemingly, the richness of detail and the complexity of artistic free-forms require a high number of high-resolution images and complex 3D modelling procedures in order to be able to adequately describe the shape of the object. For these reasons, until recently, the use of manual or semi-manual photogrammetric methods have prevented or severely limited complete three-dimensional surveys. This was obviously true in the period of analogue photogrammetry (before 2000), but remained so with the advent of digital photography (2000-2010), since photogrammetric processing operations, in one way or the other, remained a manual operation (Fassi and Campanella 2017).

In recent years (from 2010 onwards), there have been important developments in close-range photogrammetry thanks to the application of Computer Vision algorithms, able to automatize the processes of tie-point identification, camera calibration, image orientation and dense DSM reconstruction (image matching), thus allowing for accurate $3 \mathrm{D}$ reconstructions.

These methods are called 'image-based techniques': they integrate photogrammetric concepts of image orientation and camera calibration with CV algorithms for key point identification and dense image matching (Fassi et al. 2013). Today, both in literature and in practice, these methods are also called 'image scanning techniques', or 'photoscanning'. We find this terminology misleading, but the nomenclature underlines the main important tasks that they propose: the 3D dense reconstruction of the object as a 3D point cloud, comparable to laser scanner data in terms of achievable resolution and accuracy in surface description.

Furthermore, image-based methods have additional positive aspects:

- Flexibility: with the same camera, it is possible to survey both large objects (such as a building or entire archaeological sites) and small objects. The point cloud density depends solely on the image's resolution and the capture geometry.

- Accuracy knowledge point by point. The 3D position of each reconstructed point is a mathematical operation; for this reason, it is possible to know the accuracy of each point.

- Metric chromatic mapping in the 3D model.

- Self-calibration of the camera system which allows the use of normal photographic systems, as well as alternative image systems such as fisheye lenses, panorama cameras, multi-camera systems, low-cost action cameras or even micro cameras (including mobile phone cameras).

In this way, the photographic acquisition is freed from the photogrammetric constraints of the past: the great flexibility and 'easy acquisition', typical of photography 
allow for freedom of movement around the object and a multiscale acquisition while also offering the possibility to survey both very complex and large object as well as tiny decorations.

Another important advantage is that all these characteristics also allow for low-cost surveys in cases of emergency, where one can use common tools and obtain a metric result nonetheless. The final accuracy of the process can always be calculated (and this is the photogrammetric meaning of the word 'metric'!); it will be numerically similar to the resolution of the images with some pejorative variations that are strictly dependent on photographic quality.

\section{Case Studies}

The 3D survey group, as part of the ERC Project LIFE, is currently testing low-cost digital tools on two archaeological sites, characterized by different environmental and logistic conditions.

Umm al-Dabadib is located on the outskirts of the Kharga Oasis, one of the five largest oases in Egypt's Western Desert. It consists of a vast and well-preserved Roman installation including an inhabited area served by an extensive agricultural system, certainly active in the Third and Fourth Centuries AD. The site was probably abandoned at the beginning of the Fifth Century and, apart from a short-lived occupation dating back to the early Twentieth Century, it survived up to today relatively intact and virtually unknown.

Briefly described in the early Twentieth Century (Beadnell 1909), its real extent was only revealed in 1998 (Rossi 2000); it was then studied for the first time in some detail between 2001 and 2007 by the North Kharga Oasis Survey (NKOS, Rossi and Ikram 2018). Between 2012 and 2014, its agricultural system was the object of a specific study by the Old Agricultural Sites and Irrigation Systems (OASIS) project of the MUSA Centre of the Federico II University of Naples (Fassi et al. 2015; Rossi 2016; Rossi forthcoming-a); it is now the object of the multi-disciplinary project Living In a Fringe Environment (LIFE), jointly carried out by the Politecnico di Milano and the MUSA Centre and funded by the ERC CoGrant 681673 (Rossi 2017; Rossi forthcoming-b; Rossi and Fiorillo 2018; Rossi and Magli forthcoming).

This remote site is located at a distance of over $50 \mathrm{~km}$ from the nearest inhabited centre, and therefore, any activity must be planned in the absence of water, electricity and Internet. The strong winds that periodically batter the area heavily affect the integrity of any electronic device that is carried on site. Drones are not an option, as they are prohibited in Egypt; moreover, Umm al-Dabadib lies within a military area, where further restrictions apply.

In this case, the survey of the entire Fortified Settlement covering a densely builtup surface of ca. $100 \times 100 \mathrm{~m}$, and reaching peaks of over $10 \mathrm{~m}$ with the central Fort, was carried out entirely by photogrammetry (Fassi et al. 2015).

The survey work was divided into two phases - the survey of the exteriors and the survey of the interiors. To complete the survey of the external part, over 5100 
photographs were necessary. The area was divided into sub-areas corresponding to different housing units. The target was to survey the remains paying special attention to the architectural structures, with the future aim of understanding the original dimension and form of the settlement. For this goal, it was necessary to survey not only all the external parts but also the part just below the surface such as vaults, niches and holes.

The survey of open and close spaces together, thus required a multiscale approach, implemented thanks to a Canon 5D Mark III with a fixed $35 \mathrm{~mm}$ F2 lens and a Canon G1X. The professional reflex camera was mainly used for the main buildings and the largest areas, due to the high resolution $(22.3 \mathrm{Mp})$, the high-quality lenses and the major configuration possibilities. The compact one was used for the smaller buildings, for narrow spaces and when it was necessary to climb over some structures.

All the survey block was elaborated separately using Agisoft Photoscan in order to produce a high-resolution point cloud capable of representing in $3 \mathrm{D}$ the entire settlement. All the different sub-areas were registered together using markers, with the foresight to detect parts of neighbouring buildings during the survey of each subarea. The use of markers can be avoided in case of an emergency, but it is mandatory to compute the correct camera auto-calibration, to scale the final model correctly and to check the final metric results (Fassi et al. 2015).

The final results of this survey consisted of a complete and very dense point cloud of the settlement, consisting of about 650 million points, with a spatial resolution of circa $5 \mathrm{~mm}$. It is a kind of very high-density LIDAR point cloud, significantly higher than the classical resolution suitable for architectural/archaeological representation which is typical in these cases.

The second phase was to survey the internal spaces of the castle, consisting of little rooms and passages entirely or partially buried under the sand. For this reason, these spaces are dark, difficult to reach from the outside and impose strong limitations to the operator moving in them.

The survey of narrow spaces is an important topic nowadays, and many approaches are being tested in different environments in order to check the capability of 3D reconstruction, reliability of the methods and quality of the final results (Covas et al. 2015; Barazzetti et al. 2017a, b; Mandelli et al. 2017; Pepe et al. 2018). One of the proposed methods is fisheye photogrammetry, and right here, (2014) this was tested for the first time by the research group. The wide angle of the lenses allows users to survey this type of spaces based on a lower number of photos (Perfetti et al. 2017).

To overcome the lighting problem, we used speedlight when the spaces were small enough to avoid the problem of image vignetting. In this case, a light painting technique was used to uniformly illuminate the scenes. Fisheye photogrammetry was used to survey the staircase of the tower and the little rooms at the ground level of the castle. The use of the consumer camera Canon EOS350D coupled with a fixed $8 \mathrm{~mm}$ focal length and no ideal illumination devices was enough to get the geometry of the spaces with an accuracy suitable for a 1:50 scale representation even if the quality of the texture is insufficient for a qualitative description of the spaces. In order to register external and internal spaces, it was necessary to have a good overlapping zone between the two areas; it was a difficult task due to the narrow passages that 


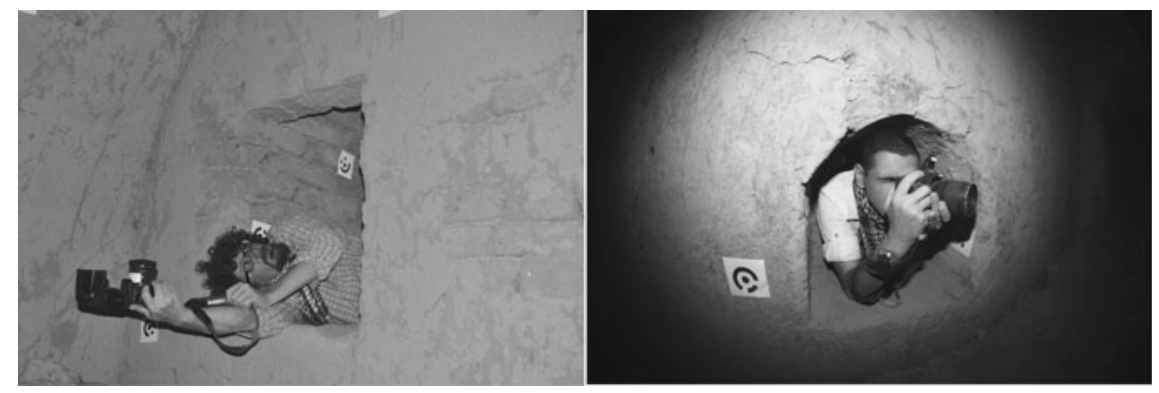

Fig. 1 Survey of the interiors of the castle in Umm el Dabadib. Fisheye photogrammetry was necessary to model the narrow and dark spaces, not easily accessible because of their reduced dimensions, as well as because sand and debris from the upper parts of the building, that collapsed in the past, flowed in and occupied accesses and corridors. Francesco Fassi and Alessandro Mandelli on the field in 2014 and 2015, surveying the windowless ground level of the castle. The same method was used to survey the building's staircase, which served all five floors, and revolved around a central pillar

connect the two areas. The use of reference markers was also in this case mandatory in order to guarantee the success of the operation (Fig. 1).

In the survey of the Fortified Settlement of Umm al-Dabadib, using a laser scanner was impossible due to the extremely complex logistic and environmental constrains (the electricity supply on site is guaranteed only by a generator, and the frequent sand-laden wind would damage the fragile components of expensive machines).

Even if using a scanner had been possible, the layout of the spaces, the wealth of details and the presence of narrow spaces would have made that type of survey longer and more difficult, as the acquisition would have implied a high number of scans, the need to continuously re-position the laser, together with all the ensuing registration problems.

For all these reasons, photogrammetry was the winning choice for this type of application, allowing complete and high-quality results in the open spaces. The 'almost impossible' challenge to perform the 3D survey of narrow spaces became possible thanks to the use of low-cost consumer sensors.

The double-phased survey was necessary to complete the $3 \mathrm{D}$ reconstruction of a very complex environment allowing for a full comprehension of the spaces (Fig. 2). The ensuing results allowed the team to start a metrological research into the planning and building methods used by the ancient builders, which otherwise would have been impossible (Rossi and Fiorillo 2018).

Another application of digital imaging for archaeology has been tested on the field at Saqqara (Egypt), on the joint Dutch-Italian excavation of the New Kingdom necropolis conducted by the Museo Egizio, Turin and the Rijksmuseum van Oudheden, Leiden. The area host a number of tombs of high officials who served the pharaohs of the Eighteenth and Nineteenth Dynasties, surrounded by minor burials and covered by later layers of occupation; they were progressively discovered and excavated from the '80s onwards (Martin 1989, 1991, 1997, 2001; Raven 1991, 2005; 


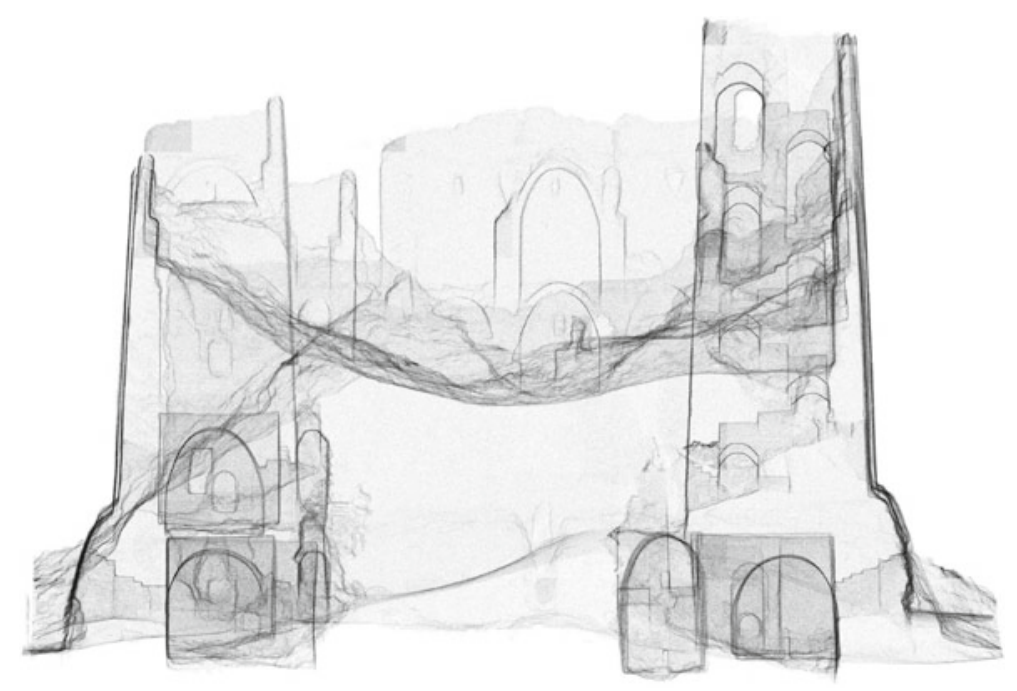

Fig. 2 A 'radiography' of the castle showing the relationship between internal and external spaces of the castle (elaboration by Fiorillo 2018)

Raven and van Walsem 2014). The area currently under excavation stretches north of the Eighteenth Dynasty Tomb of Maya and appears to include a slightly later middle-sized tomb and several Ramesside burials that reused older underground structures.

The proximity to the Nile Valley and the presence, at a short distance, of a fully equipped dig house allows the team to benefit from regular access to electricity, as well as Internet connection. Other environmental and legal restrictions apply here as well: drones are banned, and the sandy wind tends to damage fragile equipment. Photogrammetry was also chosen in this case as the main working tool.

Specific to this project is the need to record in $3 \mathrm{D}$ every single context that is excavated, to construct a virtual digging diary of the activities, to be later examined, to visualize the layers that have been removed and double-check meaningful details. Surveying contexts means surveying the same area several times in a row as it evolves and measuring relatively small flat surfaces combined with structures and small remains. In this case, therefore, the main goals are as follows:

- Global georeferencing all the surveys together, in order to visualize all the excavation phases in the correct position. This operation must be very accurate because the positioning of the different contexts in the $Z$-axis is crucial. Most of the time, the contexts consist of very thin layers, and millimetric accuracy is necessary in order to place them in their correct position and avoid false intersections or misalignments.

- Very high-resolution survey, in order to distinguish different contexts, a very large representation scale is necessary. The different layers can be distinguished only by different granulometry of the materials or small colour differences that should 
be shown as to allow for the future visualization, study and interpretation of the data.

- Near real-time elaboration, in order to facilitate the digital cataloguing of all the information, the survey team should produce the 3D models of the context quickly, ideally in parallel to the excavation.

Close-range photogrammetry is the only possible method that allows the team to satisfy all of these requirements, both individually and as a group. The most important aspects of this method, in fact, correspond closely to the necessities listed above. Its main characteristics are as follows:

- great flexibility in terms of achievable resolution, thus able to cover all the various needs of an archaeological excavation, ranging from relatively vast areas, to groups of finds (cf. Figs. 3, 4 and 6);

- the possibility of placing thin and tiny contexts in their correct absolute and relative position (Figs. 4 and 5);

- the possibility of using exactly the same instruments to perform the survey of objects of significantly different shapes and dimensions (cf. Fig. 6, showing the extremely detailed survey of a nearly vanished graffito on a limestone block which was crucial for the interpretation of the later use of that tomb);

- the possibility to achieve very large representation scales, up to 1:1 (see Figs. 4 and 6);

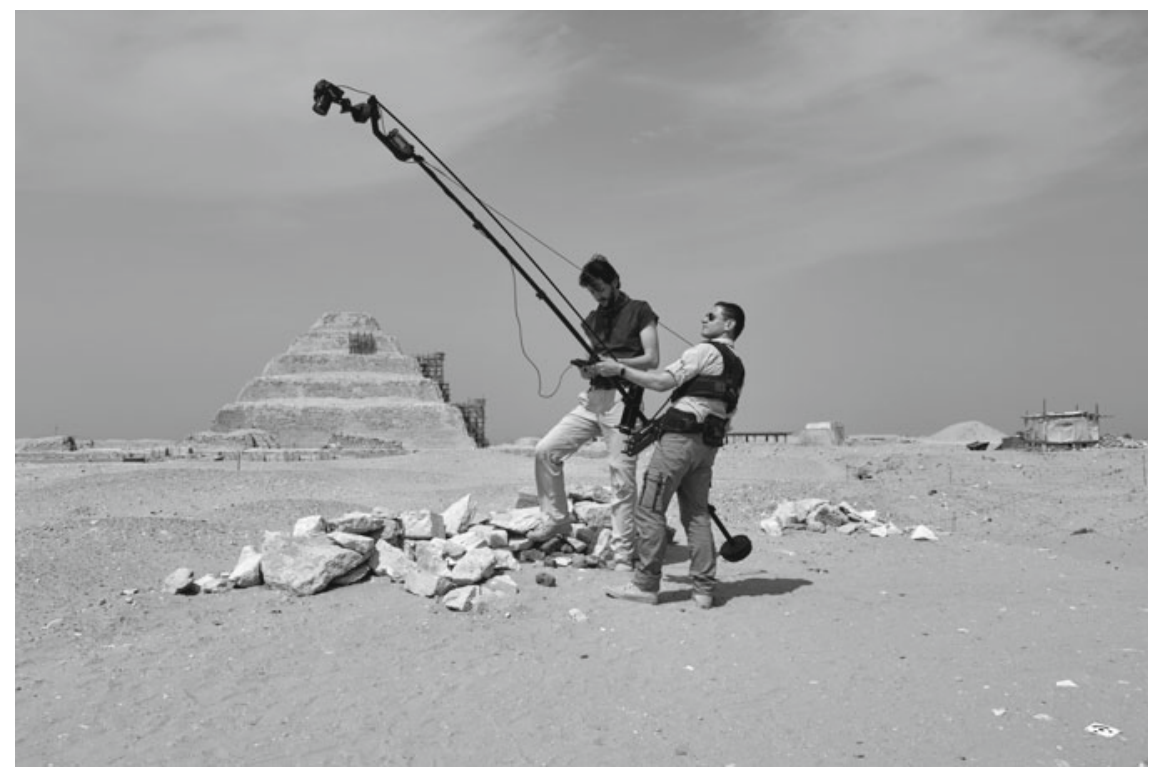

Fig. 3 Alessandro Mandelli and Luca Perfetti using a photographic crane to survey the area just excavated by the Dutch-Italian Mission to Saqqara, April 2019 


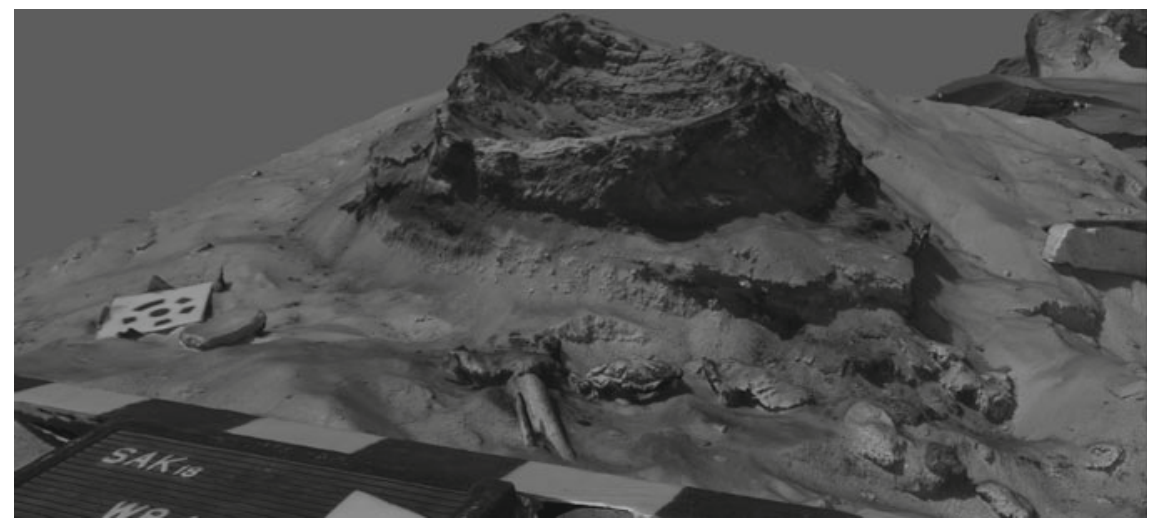

Fig. 4 The textured model of a context. It can be visualized up to a representation scale of 1:1 thanks to a texture resolution of $0.5 \mathrm{~mm}$. This represents a useful tool for archaeologists, who can virtually revisit the site and double-check details weeks or months after the excavation, in a very realistic way

- being a fast procedure, the possibility of repeating the survey many times throughout the same day, following the excavation phases step by step. The same find, for instance, can be surveyed several times as it slowly emerges from the surroundings, thus recording with precision its original context. This is extremely important, since an archaeological excavation is a destructive process, that physically removes what is found and separates the finds from one another and from their original context. What is not recorded on the spot is lost, both in terms of information and in terms of precision.

The described approach is what we use during the survey activity to support the excavation in Saqqara. A topographic network around the excavation area was measured to geo-reference all the micro-surveys together-a Canon 5D Mark III with $35 \mathrm{~mm}$ or $20 \mathrm{~mm}$ lenses was the camera used for photographic acquisition. For the smaller contexts, the resolution of $0.1 \mathrm{~mm}$ was ensured. A minimum of four targets were positioned around the scene using four long nails to anchor them into the sand for the short survey time (cf. Fig. 4). The markers were measured with a total station (Topcon ES62) and removed after every single survey operation.

For larger areas, the camera was mounted on a transportable photographic crane reaching a height of $3 \mathrm{~m}$ to capture the scene from a high vertical point of view with a GSD of less than $1 \mathrm{~mm}$ (Fig. 3). It was necessary to adopt this system due to the impossibility of using UAVs. 


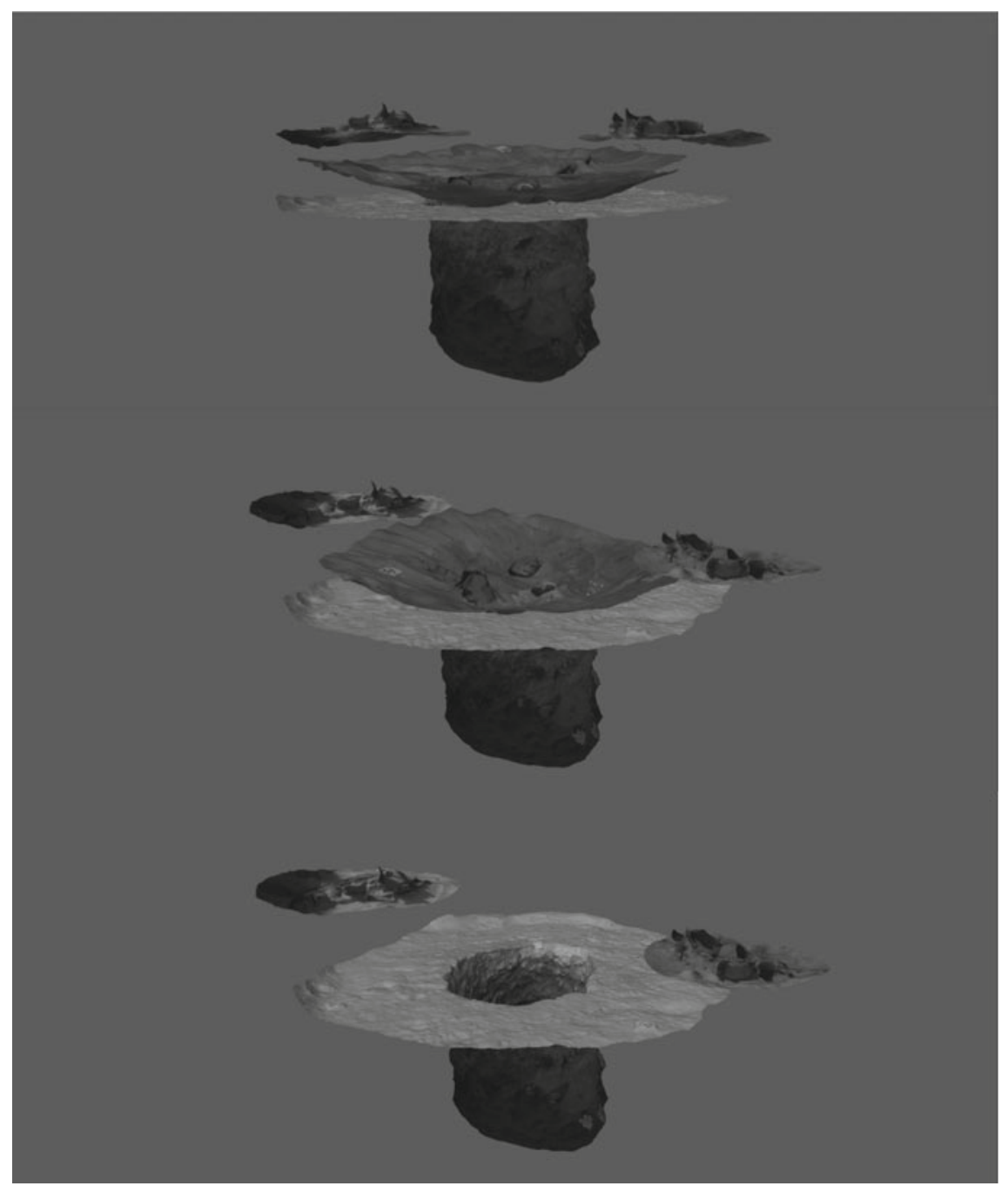

Fig. 5 A temporal sequence of excavated contexts from the 2018 excavation of the Dutch-Italian archaeological mission to Saqqara, of the Museo Egizio, Turin and the Rijksmuseum van Oudheden, Leiden: a number of 'embalming caches' are found and recorded around a burial shaft. Embalming caches contained the remains of the materials used during the mummification process and were buried near the tomb 


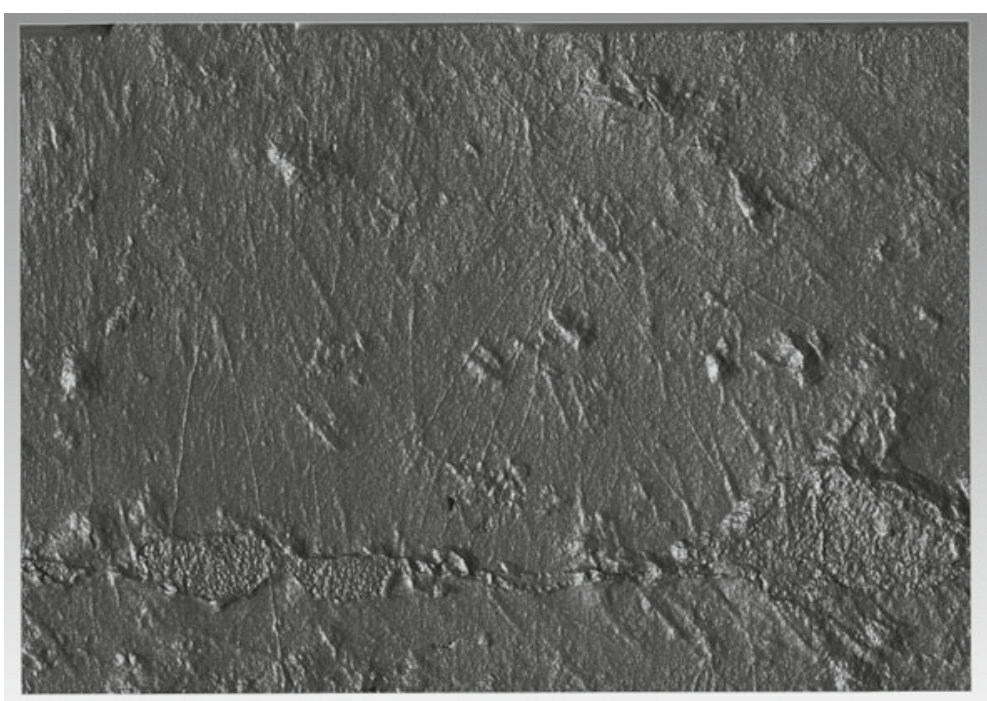

Fig. 6 A very high-resolution model of a graffito from the tomb of Horemheb at Saqqara. The original images were taken with $0.03 \mathrm{~mm}$. The matched model is in full resolution and allows us to read 3D details hardly visible to the naked eye

\section{Conclusions}

The presented case studies aim to demonstrate how nowadays it is possible to survey complex environments using low-cost tools and yet fully exploit the potential of image-based techniques. Moreover, not only can photogrammetry replace other survey methods (e.g. laser scanning) and give similar results, but in some cases, such as those described here, photogrammetry actually becomes the best and only viable solution.

The possibility of using the same camera to survey both architecture and small objects and offer the adequate resolution for each case, the flexibility in their use, and their low-cost characteristics represent the key factors for preferring this method to the classical ones of a range-based 3D survey. Different rules and procedures must be carefully followed in order to obtain metric and accurate results. Topographic support is highly recommended to geo-reference all the data together, to scale the different surveys, and to assess the final result. The use of markers or 'natural constraint points' is mandatory for the global correctness of the photogrammetric process (Fassi and Campanella 2017). 


\section{References}

Barazzetti L, Previtali M, Roncoroni F (2017a) Fisheye lenses for 3d modeling: evaluations and considerations. In: International archives of the photogrammetry, remote sensing and spatial information sciences, Nafplio, Greece, vol XLII-2/W3, pp 79-84. https://doi.org/10.5194/isprsarchives-xlii-2-W3-79-2017

Barazzetti L, Previtali M, Roncoroni F (2017b) 3D modelling with the Samsung gear 360. In: International archives of the photogrammetry, remote sensing and spatial information sciences, Nafplio, Greece, vol XLII-2/W3, pp 85-90. https://doi.org/10.5194/isprs-archives-xlii-2-w3-852017

Beadnell HJL (1909) An Egyptian oasis, London

Covas J, Ferreira V, Mateus L (2015) 3D reconstruction with fisheye images strategies to survey complex heritage buildings. In: 2015 digital heritage, Granada, pp 123-126. https://doi.org/10. 1109/digitalheritage.2015.7413850

Fassi F, Campanella C (2017) From daguerreotypes to digital automatic photogrammetry. Applications and limits for the built heritage project. In: International archives of the photogrammetry, remote sensing and spatial information sciences, vol XLII-5/W1, pp 313-319. https://doi.org/10. 5194/isprs-archives-XLII-5-W1-313-2017

Fassi F, Fregonese L, Ackermann S, De Troia V (2013) Comparison between laser scanning and automated $3 \mathrm{~d}$ modelling techniques to reconstruct complex and extensive cultural heritage areas. In: International archives of the photogrammetry, remote sensing and spatial information sciences, vol XL-5/W1, pp 73-80

Fassi F, Rossi C, Mandelli A (2015) Emergency survey of endangered or logistically complex archaeological sites. In: International archives of the photogrammetry, remote sensing and spatial information sciences, vol 40, no 5, pp 85-91

Mandelli A, Fassi F, Perfetti L, Polari C (2017) Testing different survey techniques to model architectonic narrow spaces. In: International archives of the photogrammetry, remote sensing and spatial information sciences, XLII-2/W5, pp 505-511. https://doi.org/10.5194/isprs-archives-XLII2-W5-505-2017

Martin GT (1989) The Memphite tomb of Horemheb, commander-in-chief of Tut'ankhamūn, I: the reliefs, inscriptions, and commentary. Egypt Exploration Society, Excavation Memoir 55, London

Martin GT (1991) The hidden tombs of Memphis, London

Martin GT (1997) The tomb of Tia and Tia, a royal monument of the Ramesside period in the Memphite Necropolis, London

Martin GT (2001) The tombs of three Memphite officials: Ramose, Khay and Pabes, London

Pepe M, Ackermann S, Fregonese L, Fassi F, Adami A (2018) Applications of action cam sensors in the archaeological yard. In: International archives of the photogrammetry, remote sensing and spatial information sciences, vol XLII-2, pp 861-867. https://doi.org/10.5194/isprs-archivesXLII-2-861-2018

Perfetti L, Polari C, Fassi F (2017) Fisheye photogrammetry: tests and methodologies for the survey of narrow spaces. In: International archives of the photogrammetry, remote sensing and spatial information sciences, vol XLII-2/W3, pp 573-580. https://doi.org/10.5194/isprs-archives-XLII2-W3-573-2017

Raven MJ (1991) The tomb of Iuredef. A Memphite official in the Reign of Ramesses II, London and Leiden

Raven MJ (2005) The tomb of Pay and Raia at Saqqara, London and Leiden

Raven MJ, van Walsem R (2014) The tomb of Meryneith at Saqqara. PALMA 10, Brepols

Rossi C (2000) Umm el-Dabadib, Roman settlement in the Kharga Oasis: description of the visible remains. With a note on 'Ayn Amur. Mitteilungen des Deutschen Archäologischen Instituts Kairo $56: 235-252$

Rossi C (2016) Italian mission to Umm al-Dabadib (Kharga Oasis): season 2014-preliminary report. Mitteilungen des Deutschen Archäologischen Instituts Kairo 72:153-172 
Rossi C (2017) Survey, conservation and restoration in Egypt's Western Desert: combining expectations and context. Restauro Archeologico 2:4-19

Rossi C (forthcoming-a) Italian mission to Umm al-Dabadib (Kharga Oasis): season 2015-preliminary report. Mitteilungen des Deutschen Archäologischen Instituts Kairo 74

Rossi C (forthcoming-b) Searching for the right words: what happened in Kharga in the IV century $\mathrm{AD}$ ? In: Proceedings of the colloquium Marges et frontières occidentales de l'Égypte, Cairo, 2-3 Dec 2017, Bibliothèque d'Étude

Rossi C, Fiorillo F (2018) A metrological study of the Late Roman Fort of Umm al-Dabadib, Kharga Oasis (Egypt). Nexus Netw J 20(2):373-391

Rossi C, Ikram S (2018) North Kharga Oasis survey. Explorations in Egypt's Western Desert. British Museum Publications on Egypt and Sudan 5, Leuven

Rossi C, Magli G (forthcoming) Wind, sand and water: the orientation of the Late Roman Forts in the Kharga Oasis (Egyptian Western Desert). In: Magli G, Antonello E, Belmonte JA, César González-García A (eds) Archaeoastronomy in the Roman world, Berlin

Open Access This chapter is licensed under the terms of the Creative Commons Attribution 4.0 International License (http://creativecommons.org/licenses/by/4.0/), which permits use, sharing, adaptation, distribution and reproduction in any medium or format, as long as you give appropriate credit to the original author(s) and the source, provide a link to the Creative Commons license and indicate if changes were made.

The images or other third party material in this chapter are included in the chapter's Creative Commons license, unless indicated otherwise in a credit line to the material. If material is not included in the chapter's Creative Commons license and your intended use is not permitted by statutory regulation or exceeds the permitted use, you will need to obtain permission directly from the copyright holder. 